\title{
Produção de alho em função de diferentes níveis de água e esterco bovi- no no solo.
}

\author{
João Paulo L. Melo; Ademar P. de Oliveira ${ }^{2}$ \\ ${ }^{1}$ UFRPE - Colégio Agrícola D. Agostinho, 50.000-070 Recife - PE; ${ }^{2}$ CCA - UFPB - De ${ }^{\text {pto. }}$ de Fitotecnia, 58.397-000 Areia-PB.
}

\begin{abstract}
RESUMO
O alho é cultivado no período do frio, o que coincide com a época seca do ano nas regiões produtoras brasileiras. Portanto, são necessárias irrigações frequentes para suprir a necessidade hídrica da lavoura. Além da irrigação, a adubação orgânica no alho é prática rotineira, não sendo poucos os que dela fazem a única fonte de nutrientes. Assim, este trabalho teve como objetivo avaliar o efeito de diferentes níveis de água e de matéria orgânica no solo sobre a produção e qualidade do alho. O experimento foi conduzido no Centro de Ciências Agrárias da Universidade Federal da Paraíba, em Areia, em casa-de-vegetação entre maio a outubro de 1995, época fria e seca. O delineamento experimental utilizado foi blocos casualizados, com os tratamentos distribuídos em esquema fatorial $4 \times 4$. O primeiro fator correspondeu a níveis de água no solo (65, 75,85 e $100 \%$ da capacidade de campo) e, o segundo fator, a quantidades de esterco bovino curtido $(0,20,30$, e 40 t/ha). O experimento foi conduzido com três repetições e parcelas de seis plantas, espaçadas de $0,30 \mathrm{~m} \times 0,10 \mathrm{~m}$, empregando-se a cultivar Dourados. Observou-se que o comprimento das plantas aumentou à medida que elevou-se os níveis de água, atingindo $44,0 \mathrm{~cm}$ e $46 \mathrm{~cm} 60$ dias após o plantio (dap), e 45,0 cm e 47,5 cm 90 dap, nos níveis de $85 \%$ e $100 \%$ de água disponível no solo, respectivamente. O peso máximo dos bulbos (14,85 g), ocorreu com 95,15\% de água disponível no solo, enquanto a produção total máxima atingiu $4.604 \mathrm{~kg} / \mathrm{ha}$ com $97,93 \%$ de água disponível no solo. A cada ponto percentual de água disponível no solo que foi elevado correspondeu um incremento de $80,35 \mathrm{~kg} / \mathrm{ha}$ de bulbos comerciais e uma redução de $10,71 \mathrm{~kg} / \mathrm{ha}$ de bulbos não comerciais. A aplicação de esterco e a interação entre níveis de água e de esterco não influenciaram significativamente as características estudadas.
\end{abstract}

Palavras-chave: Allium sativum L., altura de plantas, peso médio de bulbos, produtividade.

\begin{abstract}
Garlic production as a function of different water levels and bovine manure in soil.

Garlic is cultivated during the cold weather period, which is also the dry season in Brazilian producing regions. Frequent irrigations are therefore needed to supply enough water to the fields. In addition to irrigation, organic fertilization in garlic is a routine practice, with many producers making it the only source of nutrients to plants. Thus, this work was carried out to evaluate the effect of different water levels and organic matter in the production and quality of garlic. The experiment was performed in the greenhouse at the Center of Agrarian Sciences, Federal University of Paraíba, in Areia county, from May to October 1995, the cool and dry season. The experiment followed a complete randomized block design with treatments distributed in a factorial $4 \times 4$ scheme. The first factor corresponded to water levels in soil $(65,75,85$ and $100 \%$ of the field capacity) and the second factor corresponded to amounts of tanned bovine manure $(0,20,30$, and $40 \mathrm{t} / \mathrm{ha})$. The experiment was conducted with three replications and plots of six plants, spaced $0.30 \mathrm{~m} \times 0.10 \mathrm{~m}$, using cv. Dourados. It was observed that plant length increased with water levels, reaching $44.0 \mathrm{~cm}$ and $46.0 \mathrm{~cm} 60$ days after planting (dap), and $45.0 \mathrm{~cm}$ and $47.5 \mathrm{~cm} 90 \mathrm{dap}$, for $85 \%$ and $100 \%$ water availability levels in soil, respectively. The maximum bulb weight (14.85 g) was reached with $95.15 \%$ of available water in soil, while maximum total production reached $4,604 \mathrm{~kg} / \mathrm{ha}$, with $97.93 \%$ of available water in soil. Each percentage increase in available water in the soil corresponded to an increase of $80.35 \mathrm{~kg} / \mathrm{ha}$ of commercial bulbs and a reduction of $10.71 \mathrm{~kg} / \mathrm{ha}$ of non-marketable bulbs. Neither the use of bovine manure, nor its interaction with levels of water in soil significantly influenced any of the characteristics.
\end{abstract}

Keywords: Allium sativum L., plant height, average bulb weight, yield.

(Aceito para publicação em 30 de outubro de 1998)

$\mathrm{P}$ ara a maioria das hortaliças, o teor de água deve ser mantido próximo à capacidade de campo para obter-se produtividade máxima. Naturalmente, isso depende da espécie, sendo as hortaliças folhosas as mais exigentes, seguindo-se as hortaliças produtoras de frutos e as tuberosas (Filgueira, 1982). A couve-flor produz uma inflorescência maior se não for submetida a estresse hídrico, a ervilha produz mais grãos por vagem se mais água for adicionada no momento da abertura das flores (Winter, 1976). Já hortaliças de frutos devem ser irrigadas cada vez que 30 a $40 \%$ da água disponível do solo tiver sido consumida (Hargreaves, 1976). No pimentão, aumento na produtividade e no número de frutos por planta são obtidos quando as plantas se desenvolvem em solo com teor de umidade constante em 85 a $100 \%$ da capacidade de campo (Oliveira, 1995). Para o alho, durante o período de desenvolvimento vegetativo, o teor de água deve ser mantido elevado, entre 70 a $90 \%$ da capacidade de campo. Durante o período de formação do bulbo também deve-se manter tal teor, visto que o bom suprimento de água nessa fase, aumenta a produtividade e evita anomalias (Filgueira, 1982).
O alho é cultivado na estação fria, que coincide com a época seca do ano nas regiões Sul e Sudeste. Portanto, são necessárias irrigações frequentes para suprir a necessidade hídrica da lavoura. A água influi efetivamente em todos os estágios de desenvolvimento da planta, razão pela qual é decisiva a informação sobre a quantidade de água a aplicar (Menezes Sobrinho, 1978). Existem muitos trabalhos sobre irrigação no alho (Menezes Sobrinho, 1978; Marouelli et al., 1993; Araujo, et al., 1994; Pola \& Biasi, 1995) mas, poucos sobre os efeitos do estresse hídrico sobre as caracte- 
rísticas de produção da planta. Entretanto, para se programar a irrigação em alho é necessário conhecer a demanda de água da planta e a capacidade de retenção de água do solo, especialmente na zona explorada pelas raízes (Raul et al., 1989). Segundo Couto (1958), resultados significativos sobre a produção de alho são obtidos com níveis de 60 a $90 \%$ de água disponível no solo. Garcia (1964) afirma que a quantidade de água útil para o alho nunca deve ser inferior a $60 \%$ da capacidade de campo, embora o nível de água necessário esteja relacionado à cultivar plantada. Cultivares de folhas largas apresentam excelentes resultados em solos que apresentam nível elevado de água disponível. Já as cultivares de folhas estreitas perfilham quando o solo apresenta cerca de $90 \%$ de água disponível.

Além da irrigação, a adubação orgânica no alho é prática rotineira, não sendo poucos os que dela fazem a única fonte de nutrientes para as plantas (Nakagawa, 1993). Sua aplicação melhora as condições químicas e físicas do solo, nutre as plantas e permite que se processem inúmeras reações vitais, facilitando ainda o aproveitamento dos adubos pelas plantas e revertendo esses benefícios em aumento do peso dos bulbos e consequentemente, aumento de produtividade (Camargo \& Barreira, 1988). Não se sabe porém, o quanto da resposta do alho à adubação orgânica se deve aos nutrientes fornecidos e o quanto se deve aos efeitos indiretos sobre as características físicas do solo (Magalhães, 1986). Algumas recomendações sugerem a aplicação de grandes quantidades de matéria orgânica, na base de 30 a 40 toneladas de esterco bovino por hectare. No entanto, sua incorporação deve ser relativamente superficial, pois caso contrário haverá uso excessivo de material (EMBRAPA, 1984).

Mascarenhas et al. (1993) observaram incremento de $71,92 \%$ na produção de alho e menor perda de peso em bulbos armazenados por $90,100,110$ e 120 dias, quando da utilização de 118 t/ha de composto orgânico. Pereira et al. (1987) não observaram aumento significativo na altura das plantas e na produção de bulbos no alho, estudando os efeitos da adubação orgânica com 10,
$20,30,40$ e 50 t/ha de composto orgânico. Seno et al. (1995) detectaram diminuição no peso médio de bulbos e na percentagem de bulbos comerciais quando empregaram 0,10 e 30 t/ha de esterco bovino associado ao fósforo.

O objetivo do presente trabalho foi avaliar os efeitos de diferentes níveis de água disponíveis no solo e da utilização de esterco bovino na produção e qualidade de bulbos de alho.

\section{MATERIAL E MÉTODOS}

O trabalho foi desenvolvido no período de maio a outubro de 1995 , em casa-de-vegetação, no Centro de Ciências Agrárias da Universidade Federal da Paraíba, em Areia. Foi utilizado um Latossolo vermelho-amarelo, com as seguintes características: $10,8 \%$ de silte; $21,40 \%$ de argila; $6,85 \%$ de água disponível; densidade aparente de 1,40 g/ $\mathrm{cm}^{3}$; capacidade de campo (0,10 Mpa) de $14,86 \%$; ponto de murcha (1,5 Mpa) de $8,01 \% ; 0,95 \%$ de matéria orgânica; $\mathrm{pH}$ em água igual a 4,7; 5,4 ppm de fósforo assimilável; $2,47 \mathrm{meq} / 100 \mathrm{~g}$ TFSA de hidrogênio + alumínio; 0,90 meq/100 g TFSA de cálcio + magnésio e 0,15 meq/100 g de potássio.

$\mathrm{O}$ delineamento experimental empregado foi blocos casualizados, distribuindo-se os tratamentos em esquema fatorial $4 \times 4$. O primeiro fator correspondeu a níveis de água disponível no solo $(65,75,85$ e $100 \%$ de capacidade de campo) e, o segundo fator, a doses de esterco bovino $(0,20,30$ e $40 \mathrm{t} / \mathrm{ha})$. Foram utilizadas três repetições e a unidade experimental constou de uma bandeja plástica com $31 \mathrm{~cm}$ de comprimento, 26 de largura e $20 \mathrm{~cm}$ de altura, sendo utilizados 9,6 kg de solo por bandeja, colocando-se seis plantas em cada.

A adubação de plantio constou de aplicações que corresponderam a 100 $\mathrm{kg} / \mathrm{ha}$ de sulfato de amônio, $396 \mathrm{~kg} / \mathrm{ha}$ de superfosfato simples e $59 \mathrm{~kg} / \mathrm{ha}$ de cloreto de potássio. Na adubação de plantio foi feita também uma calagem através de aplicação de 1,3 t/ha de calcário calcinado. As incorporações das doses de matéria orgânica foram feitas também simultaneamente à adubação de plantio. A adubação de cobertura foi realizada à base de $150 \mathrm{~kg} / \mathrm{h}$ a de sulfato de amônio, parcelados em duas aplicações, 30 e 60 dias após o plantio, seguidas de capinas manuais e aplicações de Deltametrina 2,5 E para combater tripes. O plantio foi efetuado manualmente usando-se bulbilhos de peneira 3 (Regina \& Rodrigues, 1970), colocados com ápice para cima, a uma profundidade de $5 \mathrm{~cm}$ em todas as bandejas. $\mathrm{O}$ espaçamento entre linhas foi de $0,25 \mathrm{~m}$ e de $0,10 \mathrm{~m}$ dentro das linhas. Foi empregada a cultivar Dourados.

Inicialmente a umidade do solo foi mantida em $100 \%$ da capacidade de campo e, após a emergência das plantas (dez dias após o plantio), deu-se início ao processo de diferenciação dos níveis de água no solo $(65,75,85$ e $100 \%)$. O controle da irrigação foi feito diariamente através do método de pesagem, utilizando-se balança automática com precisão de 20 gramas. A quantidade de água da unidade experimental era reposta conforme a diferenciação dos níveis de água no solo proposta anteriormente.

A colheita foi efetuada 150 dias após o plantio, contando-se as plantas colhidas e deixando-as exposta ao sol durante três dias para que se processasse a cura. Em seguida as plantas foram pesadas e acondicionadas em sacos telados e armazenadas sob temperatura ambiente, conforme a prática tradicional. Após esse procedimento foi efetuada a "toilete", que consistiu no corte do pseudocaule a $2 \mathrm{~cm}$ dos bulbos e retirada de algumas túnicas. Os bulbos limpos foram classificados e pesados para obtenção da produção comercial e não comercial (EMBRAPA, 1984).

Foram avaliadas as características comprimento de plantas 60 e 90 dias após o plantio, que correspondeu à média das seis plantas de cada unidade experimental, sendo medidas desde 0 pseudocaule até a extremidade máxima das folhas; peso médio de bulbos e; produção total, comercial e não comercial de bulbos. Os efeitos dos fatores estudados sobre as características avaliadas foram conhecidos mediante análise de variância e de regressão, tendo sido selecionado para expressar o comportamento de cada característica o modelo significativo de maior ordem e maior coeficiente de correlação. 


\section{RESULTADOS E DISCUSSÃO}

Não houve efeito significativo das doses de esterco bovino e tão pouco de sua interação com os níveis de água disponível no solo para nenhuma das características avaliadas.

\section{Comprimento das plantas}

Pela equação de regressão ajustada do comprimento de plantas 60 e 90 dias após o plantio (Figura 1), observou-se uma relação linear entre os níveis de água no solo e o comprimento das plantas. As plantas atingiram, 60 dias após o plantio, o comprimento de $44,0 \mathrm{~cm}$ com $85 \%$ de água disponível e 46,0 cm quando este nível foi elevado para $100 \%$. Noventa dias após o plantio também verificou-se um incremento no comprimento das plantas com a elevação do nível de água, com as plantas medindo $45,0 \mathrm{~cm}$ com $85 \%$ e $47,5 \mathrm{~cm}$ com $100 \%$ de água disponível. Tais resultados confirmam a exigência do alho em água durante seu crescimento vegetativo. Segundo Filgueira (1982), o teor de água nesta fase deve ser mantido em torno de 70 a $90 \%$ da capacidade de campo, para se obter crescimento máximo das plantas. Menezes Sobrinho (1978) também afirma que, na fase inicial, maior quantidade de água no solo favorece o desenvolvimento vegetativo do alho.

O fato das plantas apresentarem comprimentos menores nos níveis de água no solo inferiores a $85 \%$ está provavelmente relacionado aos efeitos do estresse hídrico no crescimento das plantas. O estresse hídrico, segundo Davies \& Zhang (1991) pode provocar mudanças nas relações hídricas nas folhas que, por sua vez afetam os processos químicos e fisiológicos e, em consequência, o crescimento e desenvolvimento da parte aérea da planta. De acordo com Scalopi (1973), o déficit hídrico nas plantas ocorre em situações em que as células e tecidos não estão plenamente túrgidas. Em consequência, se dá o fechamento dos estômatos, causando redução na fotossíntese e, consequentemente, no desenvolvimento.

A ausência de efeito das doses de esterco bovino sobre o comprimento das plantas pode estar relacionada a uma deficiência de micronutrientes, em função da complexão desses pela matéria orgânica, acarretando um menor desenvolvimento da planta (Seno et al., 1995).

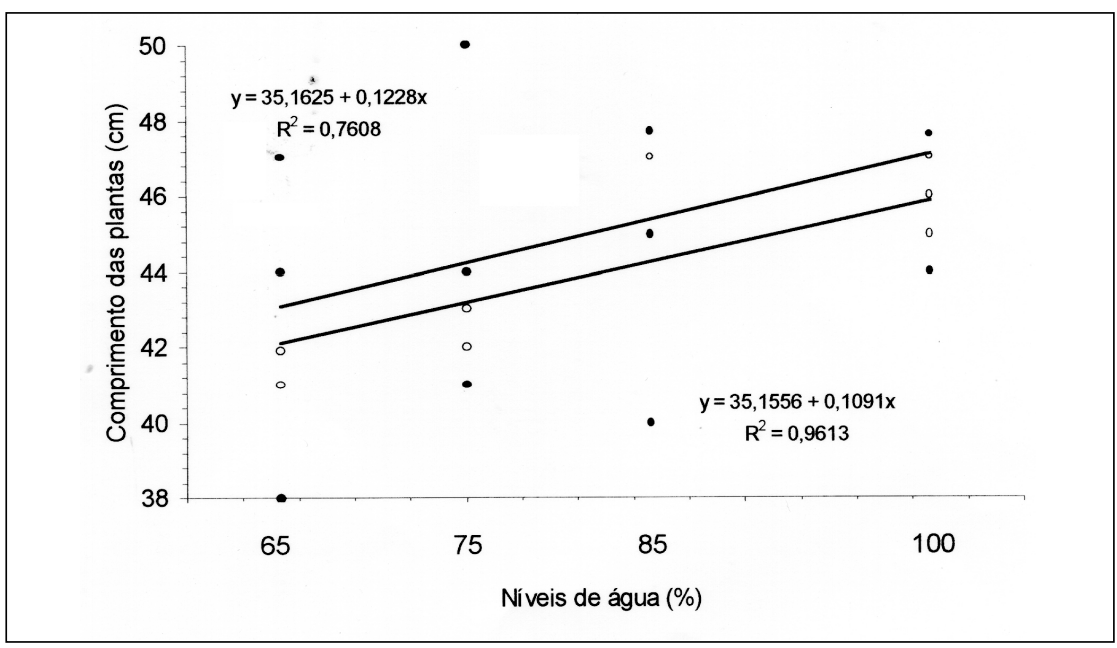

Figura 1. Efeito de níveis de água no solo sobre a altura das plantas de alho, 60 $\left({ }^{\circ}\right)$ e $90(\cdot)$ dias após o plantio. Areia, UFPB-CCA, 1995.

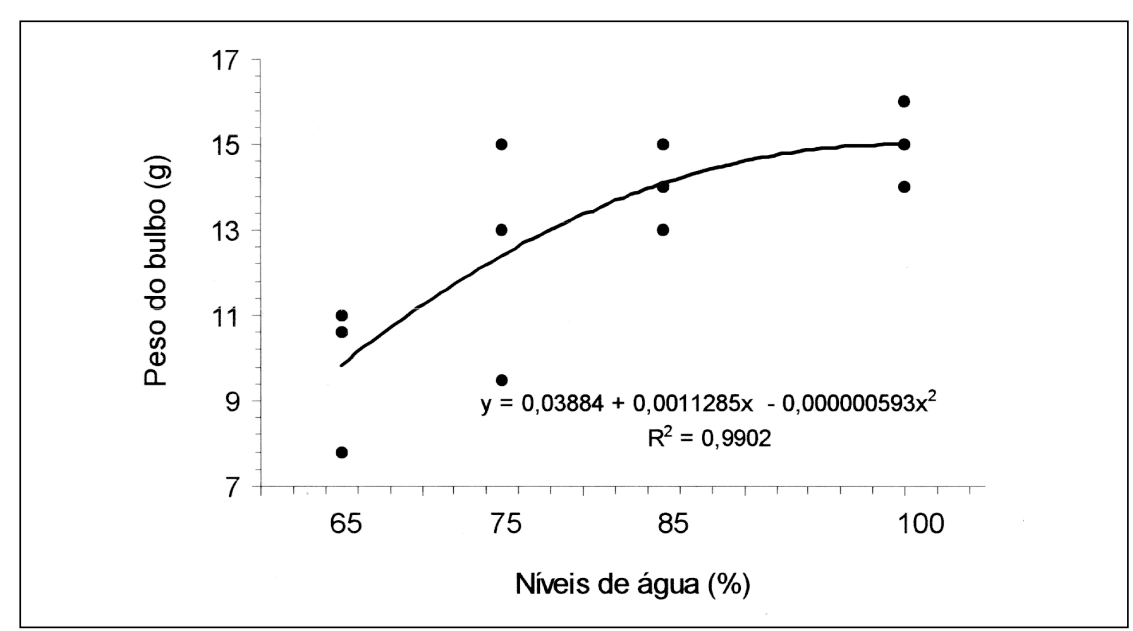

Figura 2. Efeito de níveis de água no solo sobre o peso do bulbo de alho. Areia, UFPB CCA, 1995.

\section{Peso médio dos bulbos}

O peso médio de bulbos apresentou resposta quadrática aos níveis de água disponíveis no solo. O peso médio máximo dos bulbos, estimado por derivação $(14,85 \mathrm{~g})$, ocorreu com $95,15 \%$ de água disponível no solo (Figura 2). Este peso aproxima-se da média nacional que, segundo Oliveira (1985), situa-se em 15,0 g. A existência de efeito de níveis de água comprova o fato de que para a maioria das hortaliças o teor de água deve ser mantido próximo a $100 \%$ da capacidade de campo (Filgueira, 1982). No alho, embora esteja incluído no grupo das hortaliças tuberosas, consideradas menos exigentes em água que as demais, deve ser mantido um nível de água disponível de 70 a 90\%, principalmente no período de formação dos bulbos (Couto, 1958). Na cebola, maiores exigências hídricas ocorrem também no período de formação dos bulbos (Garrido \& Caixeta, 1980). Costa filho et al. (1995) relatam que níveis acima de $80 \%$ de água disponível no solo proporcionaram maior peso médio de bulbos na cebola.

O fato do esterco bovino não ter influído no peso médio dos bulbos pode ser consequência da ausência de seu efeito sobre o comprimento das plantas. Em solo com 2,1\% de matéria orgânica, Seno et al. (1995) não obtiveram resposta positiva no peso médio de bulbos em alho com aplicação de 30 t/ha de esterco bovino, possivelmente, em consequência da redução no comprimento das plantas constatada 60 dias após o plantio. 


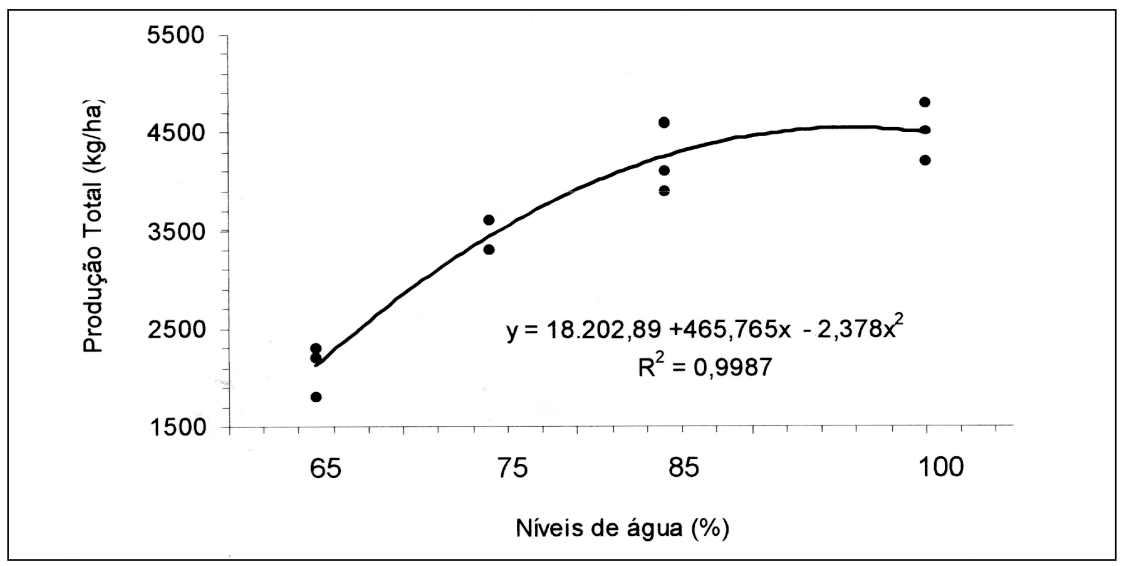

Figura 3. Efeito de níveis de água no solo sobre a produção total de bulbos de alho. Areia, UFPB - CCA, 1997.

\section{Produção de bulbos}

Pela curva ajustada a partir da equação polinomial (Figura 3), verificou-se que a produção total de bulbos atingiu ponto máximo $(4.604 \mathrm{~kg} / \mathrm{ha})$ no nível ótimo estimado de $97,93 \%$ de água disponível no solo, superando a média nacional, estimada em $4.200 \mathrm{~kg} / \mathrm{ha}$ (EMBRAPA, 1984). Em virtude do alho alcançar produção máxima no nível de água próximo ao verificado para o peso médio dos bulbos $(95,15 \%)$ (Figura 2), corrobora as correlações positivas e significativas, embora baixas, encontradas entre produção total e peso médio de bulbos $\left(\mathrm{r}=0,51^{*}\right)$ e produção total $\mathrm{e}$ altura das plantas $\left(r=0,44^{*}\right)$. Esses resultados permitem concluir que, ate certo limite, a produção total foi dependente da resposta linear do comprimento das plantas (Figura 1) à elevação dos níveis de água disponíveis no solo, o que proporcionou possivelmente aumento da taxa fotossintética, fator indispensável para a bulbificação e para acúmulo de reservas nos bulbos. Resultados similares foram obtidos por Couto (1958), que encontrou as maiores produções em alho com o nível de $90 \%$ de água no solo.

O esterco bovino não interferiu significativamente sobre a produção total de bulbos. Em solos com 5,4 a 3,6\% de matéria orgânica, Holanda et al. (1982) e Pereira et al. (1987), respectivamente, não obtiveram resposta positivas na produtividade com a utilização de esterco de gado, enquanto Lima et al. (1984), em solo com 1,4\% de matéria orgânica mais adubação química, verificaram que o emprego de $30 \mathrm{t} / \mathrm{ha}$ de esterco de gado propiciou aumento na produção de bulbos. Como o teor de matéria orgânica do solo utilizado era baixo $(0,95 \%)$, esperava-se efeito da matéria orgânica adicionada. Porém, como os efeitos da matéria orgânica se relacionam, alem do fornecimento de nutrientes, a alterações em características físicas do solo (Nakagawa, 1996), possivelmente o tempo da incorporação da matéria orgânica (sete dias antes do plantio) não tenha sido suficiente para causar alteração do solo de forma benéfica às plantas. Também é possível que a adubação química de plantio e cobertura tenham sido suficientes para fornecimento dos nutrientes exigidos pelo alho.

$\mathrm{Na}$ classificação de bulbos, a influência dos níveis de água disponíveis no solo ajustou-se a uma função linear tanto para a produção comercial $(\mathrm{Y}$ $\left.=3.369,44+80,35 x ; r^{2}=0,85\right)$ como não comercial de bulbos ( $\mathrm{Y}=1183,9875$ $\left.10,71 x ; r^{2}=0,96\right)$. Calculou-se uma elevação de $80,35 \mathrm{~kg} / \mathrm{ha}$ de bulbos comerciais e uma redução de $10,71 \mathrm{~kg} / \mathrm{ha}$ na produção de bulbos não comerciais para cada ponto percentual incrementado de umidade. $\mathrm{O}$ esterco bovino não influenciou estas características. É possível que os mesmos fatores discutidos para o peso médio de bulbos e produção total tenham contribuído também para este resultado.

\section{LITERATURA CITADA}

ARAÚJO, R.C.; SOUZA, R.J. de.; SILVA, A.M. da.; SILVA, V.F. Efeitos de cobertura morta e de frequências de irrigação sobre duas cultivares de alho. Horticultura Brasileira, Brasília, v. 12, n. 1, p. 70, 1994.
CAMARGO, C.D.; BARREIRA, P. Alho: uma planta mágica com um futuro garantido no mercado nacional. $5^{\mathrm{a}}$. ed. São Paulo: ICONE, 1988. $89 \mathrm{p}$.

COSTA FILHO, J.F. da.; CARVALHO, H.O.; SOUZA, F.O. de.; KILDEMAN, D.C. Efeitos de níveis de umidade na produção de cebola (Allium cepa L ). In: SEMINÁRIO NACIONAL DE IRRIGAÇÃO E DRENAGEM, 3., 1975, Fortaleza. Anais... Recife: MINTER/DNOCS/ABD, 1974, n. 3, p. 104 $-110$.

COUTO, F.A.A. Resultados experimentais de seleção e métodos de plantio de bulbilhos na brotação, crescimento e produção de Alho. Viçosa: UREMG, 1958. 130 p. (Tese catedrático).

DAVIES, W.J.; ZHANG, J. Root signal and regulation of growth and development of plants in drying soil. Annual Review Plant Physilogy, v. 42, p. 55 - 76, 1991.

EMPRAPA. Cultivo do alho (Allium sativum L.) Brasilia: EMPRAPA - CNPH, 1984. 16 p. (Instruções técnicas 2)

FILGUEIRA, F.A.R. Manual de Olericultura: cultura e comercialização de hortaliças. São Paulo: Agronômica Ceres, 1982. 357 p.

GARCIA, A. Influência da irrigação no crescimento, produção e superbrotamento de alho (Allium sativum $L$.). Viçosa: UFV, 1964, 45 p. (Tese mestrado).

GARRIDO, M.A.T.; CAIXETA, T.J. Irrigação em cultura de cebola. Informe Agropecuário, Belo Horizonte, v. 6, n. 62, p. 41 - 44, 1980.

HARGREAVES, G.H. Climatic and irrigation requirements for Brazil. London: Utah State University, 1976. $44 \mathrm{p}$.

HOLANDA, J.S.; MIELNICZUK, J. G. Utilização de esterco e adubo mineral em quatro seguências de culturas em solo de encosta basáltica do Rio Grande do Sul. Revista Brasileira de Ciência do Solo, Campinas, v. 6, n. 1, p. $47-51,1982$.

LIMA, J.A .; SOUZA, A.F.; CASTOR, O.S.; MENEZES SOBRINHO, J.A. de. Efeitos de matéria orgânica e vermiculita na produção de alho. Pesquisa Agropecuária Brasileira, Brasília, v. 19, n. 1, p. 41 - 42, 1984.

MAGALHÃES, J.R. de. Nutrição mineral do alho. Informe Agropecuário, Belo Horizonte, v. 12, n. 142, p. 20 - 30, 1986.

MAROUELLI, W.A.; SILVA, W.L.C.; SILVA, H.R. Manejo da irrigação subsuperficial no estágio inicial da cultura do Alho. Horticultura Brasileira, Brasília, v. 11, n. 1, p. 45, 1993.

MASCARENHAS, M.H.T.; VIANA, M.C.M.; LARA, J.F.R. Efeito de doses crescentes de composto orgânico sobre a perda de peso de bulbos de alho. Horticultura Brasileira, Brasília, v. 11, n. 1, p. 83, 1993

MENEZES SOBRINHO, J.A. de. Irrigação na cultura do alho. Informe Agropecuário, Belo Horizonte, v. 4, n. 48, p. 39 - 41, 1978.

NAKAGAWA, J. Nutrição e adubação da cultura do alho. In: SIMPOSIO SOBRE NUTRIÇÃO E ADUBAÇÃO DE HORTALIÇAS, 1., 1990, Jaboticabal. Anais... Piracicaba: Potafós, 1993. p. 341 - 380. 
OLIVEIRA, A.P. de. Efeito do bagaço de canade-açúcar associado à adubação nitrogenada sobre a produção dos alhos (Allium sativum L.) Amarante e Dourados Vicosa: UFV, 1985. 51 p. (Tese mestrado).

OLIVEIRA, E.L. de. Efeito do estresse hídrico sobre características da cultura do pimentão (Capsicum annum L.) Campina Grande: UFPB - CCT, 1995. 86 p. (Tese mestrado).

PEREIRA, E.B.; FORNAZIER, M.J.; SOUZA, L.S. de.; VENTURA, A.J.; NOGUEIRA, D.F. Efeitos da adubação orgânica com composto sobre a cultura do alho. Horticultura Brasileira, Brasília, v. 5, n. 1, p. 36 - 38, 1987.
POLA, A.C.; BIASI, J. Irrigação na cultura do alho em Latossolo branco húmico distrófico. Horticultura Brasileira, Brasília, v. 13, n. 1, p. 106,1995 .

RAUL, F.E.; NOBERTO, F.E.; CRISTIAN, N.; PERALTA, A.J. Programacion del riego para el cultivo del ajo (Allium sativum L.). Agricultura Técnica, v. 50, n. 45, p. 337-342, 1989.

REGINA, S.M.; RODRIGUES, J.V. Peneiras já classificam o alho-planta. Belo Horizonte: ACAR, 1970. 6 p. (Comunicado técnico).

SCALOPI, W.J. Efeitos de déficts hidricos em diferentes estágios fenológicos de batata (Solanum tuberosum L. ). Botucatu: UNESPFCA, 1973. 104 (Tese mestrado)
SENO, S.; SALIBA, G.G.; PAULA, F.J.; ROGA, F.S. Efeito de fósforo e esterco de curral na cultura do alho (Allium sativum L.) Cv. Roxo de Caçador. Horticultura Brasileira, Brasília, v. 13, n. 2, p. $196-199,1985$.

SINGH, J.R.; TIWARI, J. Efect of source of organic manures and levels of growth caractheristics of Allium sativum L. (garlic). Indian Journal, v. 25, n. 3, p. 191 - 195, 1968.

WINTER, E.J. A água, o solo e a planta. São Paulo: EPU, 1976. 169 p. 